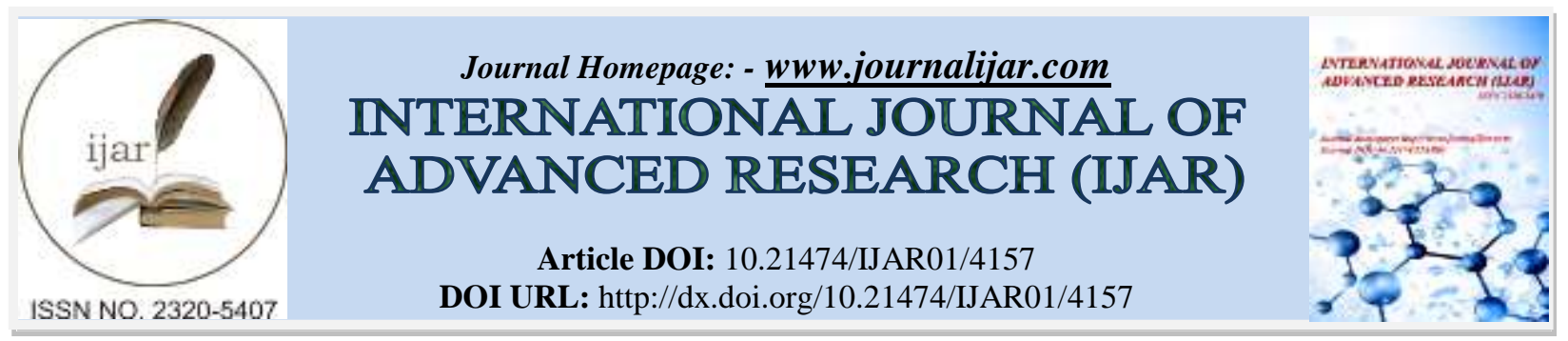

RESEARCH ARTICLE

\title{
OUTCOME OF UNSTABLE INTERTROCHANTERIC FRACTURE HIP TREATED WITH PROXIMAL FEMORAL NAIL- A PROSPECTIVE STUDY OF 50 CASES.
}

\section{Dr. Ghaniuzzoha Asadi ${ }^{1 *}$ and Dr.Suyash Kothari ${ }^{2}$.}

1. M.S.(Orthopaedics), Specialist Medical Officer in Orthopaedics, Mumbai.

2. M.S.(Orthopaedics), Clinical Associate In Orthopaedics, Mumbai.

\section{Manuscript Info}

Manuscript History

Received: 04 March 2017

Final Accepted: 04 April 2017

Published: May 2017

Key words:-

proximal femoral nail; unstable intertrochanteric fracture, hip fracture.

\section{Abstract}

Background: Hip fracture in elderly patients is a very devastating complication of osteoporosis and has serious complications leading to serious threat to patient's mobility \& social life and sometimes causing death.

Aims \& Objectives:To report outcome of 50 consecutive patients having unstable intertrochanteric fracture hip treated with a proximal femoral nail (PFN), a recently introduced cephalomedullary nail by AO.

Materials \& Methods:Total 50 patients sustaining unstable intertrochanteric fractures due to any cause, as classified by $\mathrm{AO}$ underwent proximal femoral nailing with a lag screw, and an anti rotational hip Screw during the period of August 2013 to January 2016. The most common fracture type was A2.2 $(n=25)$, followed by A2.3 $(n=15)$ and A3.1 $(n=3)$ and A3.3(n=7) The position of the tip of lag screw within the femoral head was measured from the center of the head in AP and lateral views, intra operatively, post operatively and in follow ups.. The lateral slide of the lag screw after fracture consolidation was measured by comparing the immediate postoperative and final anteroposterior radiographs.

Results:90\% of lag screws were placed in an optimal position(i.e, inferiorly on AP view and centrally in lateral view). The length of lateral slide leading to telescoping effect of the lag screw in A2.2 fractures was significantly less than that in A3.3 fractures which are highly communited suggesting that free sliding of the lag screw facilitates direct impaction between fragments.

Discussion: Compared to laterally placed slide plates, PFN decreases the bending forces upto $25-30 \%$ and in comparison with previous intramedullary devices e.g gamma nails, it showed significant less cutout rates due to an additional antirotational hip screw, with more suitable biomechanical properties.

Conclusion. A PFN is optimum implant for the treatment of unstable inter trochanteric fracture hip.

Copy Right, IJAR, 2016,. All rights reserved. 


\section{Introduction:-}

Though intertrochanteric region is a very common site of fractures in elderly population constituting almost half of all the fractures occurring in proximal femur, unstable intertrochanteric fractures are never lasting challenge for an orthopaedic surgeon due to post operative loss of reduction and medialisation of femoral shaft leading to early or late implant failure on weight bearing[1,2]. The operative treatment of intertrochanteric fractures has been a matter of debate and a number of fixation devices have been used with varying degrees of success[3,4,5\&6]. Screw and side plate devices reliably stabilize stable fracture patterns but unstable fractures require a mechanically optimized device and better implant purchase in the femoral head[7-11].And reoperation rate mentioned in literature is in order of $4 \%$ for stable fractures to $29 \%$ for most unstable fractures[12-16].

\section{Materials And Methods:-}

Between August 2013 to January 2016, we randomized 50 patients of unstable intertrochanteric fractures prospectively according to AO/OTA classification \& they were treated using standard short proximal femoral nail selected for the study and written acceptance was taken from the ethical committee.

Almost all the patient in this study had come to the hospital immediately after trauma or within one week of injury. Plain radiographs AP and lateral view was obtained at the time of admission and and all fractures were categorised according to the AO/ASIF Classification(Fig.1),Unstable intertrochanteric fractures include A2.2 to A3.3.25 patients were having A2.2 type, 15 had A2.3 type, 3 had A3.1 and 7 had A3.3 type of fractures.

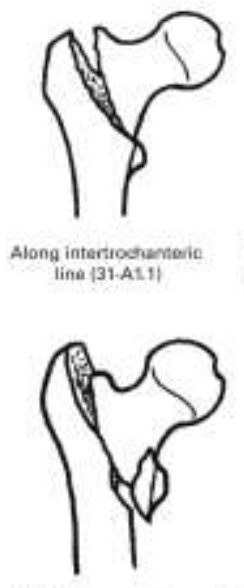
With 1 imermediate
fragment (31-A2-1)

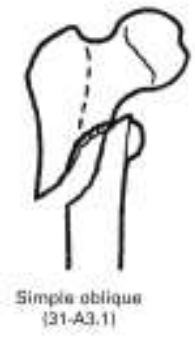

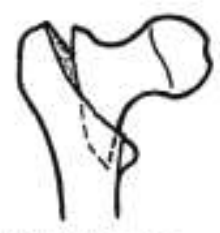

Through the graver

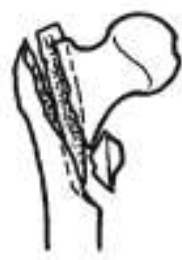

With severai imemersate
fragments $[31-A 2.2]$

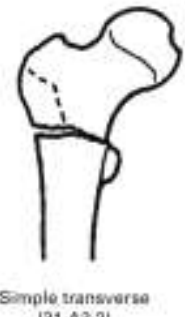

|31-A3.21
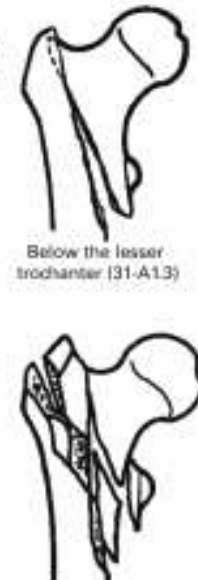

Extanding mane than $1 \mathrm{em}$ beiow lesage loochanter

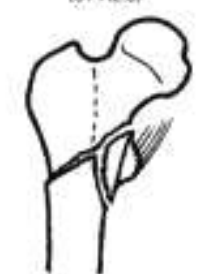

Mutifragmentary (31.233)

Fig 1:- AO/ASIFClassification

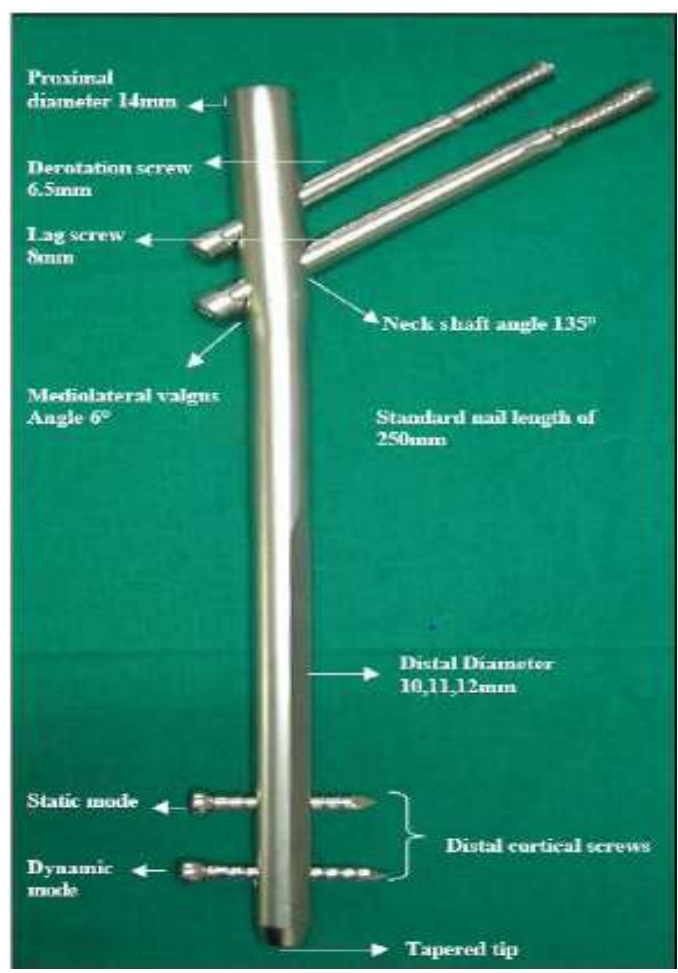

Fig 2:- Proximal Femoral Nail

\section{Inclusion Criteria:-}

- Adult patients with closed growth plate.

- Patients sustaining trauma and consulted for the first time all consecutive patients having unstable trochanteric fractures and fulfilling above criteria and treated with PFN were included. 


\section{Exclusion Criteria:-}

- Patients with open physis.

- All pathological fractures.

- A patient with penetrating local wound due to road traffic accident.

- Previous surgery on proximal femur.

\section{Pre Operatively:-}

- All the patients were admitted through the out patient department or through casualty.A complete history regarding the nature of trauma, the side of injury, the duration since the trauma and history of associated injuries or any other medical or surgical ailment was taken.

- Thorough clinical evaluation of the injury and systemic examination was done.

- Radiological confirmation of the diagnosis was carried out by taking anteroposterior and lateral $\mathrm{x}$-rays of hip and the fractures were classified according to AO/OTA classification.

- Routine laboratory investigation of blood, X-ray of the chest and ECG and special investigation like 2D echocardiography and other required investigations done in indicated patients.

- Every patient was given a below knee skin traction and the limb was suspended on a Bohler's Splint with about $3 \mathrm{~kg}$. weight.Analgesics were also started immediately on admission.

- All cases were operated within the first week of sustaining trauma after stabilizing the patient and obtaining preanesthetic clearance.

\section{Operative Procedure:-}

Most of the surgeries were done under spinal anaesthesia and some were done under combined spinal and epidural anaesthesia or general anaesthesia.The surgery was done upon standard fracture table and under Carm Guidance.All cases were operated using short PFN with $250 \mathrm{~mm}$ length and diameter $9 \mathrm{~mm}, 10 \mathrm{~mm}, 11 \mathrm{~mm} \&$ a $8 \mathrm{~mm}$ lag screw inferiorly and $6.5 \mathrm{~mm}$ derotational screw superiorly in head of femur \& 2 distal $4.9 \mathrm{~mm}$ screws one static and one dynamic(Fig-2).Reduction achieved in closed means and postoperative images were taken.

\section{Post Operative Protocol:-}

- Parenteral antibiotics, usually third generation cephalosporin, were given just before induction and continued postoperatively atleast for three days.

- Static quadriceps exercises in sleeping posture were started as early as patient is out of anaesthetic effect..

- Check x-rays are taken on the same day as soon as patients was stablizied following the surgery.

- Depending on the type of fracture, stability and age, assisted partial weight bearing was started usually on the second postoperative day.Patient were discharged on the $5^{\text {th }}$ post operative day if no post operative complication was present.

- $\quad$ Patients were followed up usually on $12^{\text {th }}$ post operative day for stitch removal and at six weeks, 3 months and 9 months after discharge. Plain AP and lateral radiographs were obtained at each visits. All changes in the position of the fracture and implant, when compared with the post-operative radiographs, were recorded and considered as secondary measures of outcome.

- Clinical assessment of fracture union, range of movement of hip and knee and radiological assessment of fracture union was done on follow up.

- If clinical union was found satisfactory and radiological union was found to be in progress full weight bearing was started. Patients were next called at 9 months and reassessment, both clinical as well as radiological was done.

\section{Results:-}

Inter trochanteric fracture commonly occur in elderly patients but increased mechanisation and increased number of road traffic accidents results in this fracture occurring even in younger patients more commonly of unstable variety,directly related to magnitude of trauma. In elderly people, intertrochantric fracture is usually caused by minor trauma, usually a domestic accident like fall in bathroom or fall from stair generally in $6^{\text {th }}$ decade and then after, while in young patients a major trauma like vehicular accident and less commonly fall from height is the cause of this fracture. 
Average age of the patients in the present study found to be 55.8 years with 26 females and 24 males.Fall at home was the most common cause of fractures in $56 \%$ followed by road traffic accidents in $28 \%$. AO classification was used. A2.2 was the most common fracture type found followed by A2.3 and A3.3 with marginal difference.

The reduction was assessed by IITV and check X-ray and found to be stable in $80 \%$ and unstable in $20 \%$ considered from restoration of posteromedial calcar region. In AP radiographs, $100 \%$ of lag screws appeared to be placed in the inferior part of the femoral head. In lateral radiographs, $90 \%$ of lag screws appeared to be placed centrally, $8 \%$ posteriorly, and $2 \%$ anteriorly. The optimal position-inferior on APview and central on lateral view-was achieved in $45 / 50(90 \%)$.
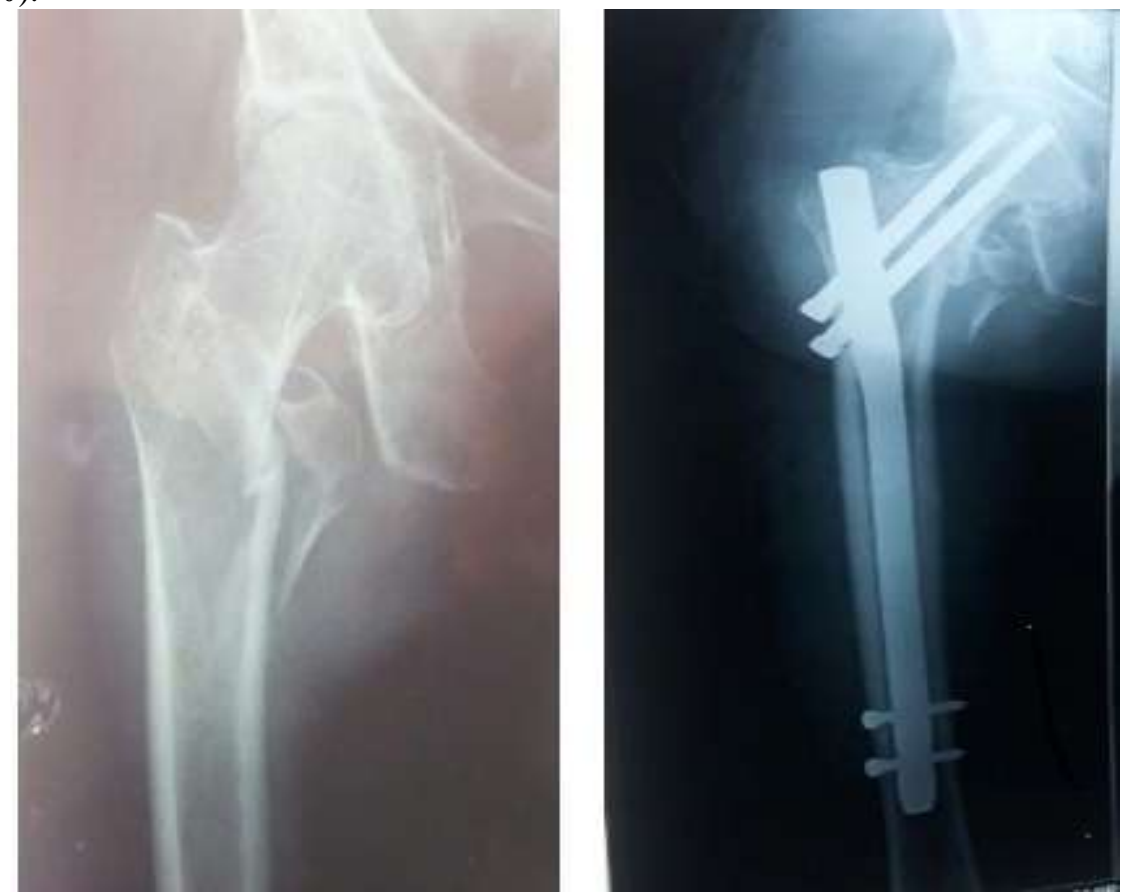

Fig-3:- Preoperative Xray of Unstable Fracture hip and post operative Xray after fixation with Proximal Femoral Nail(PFN).
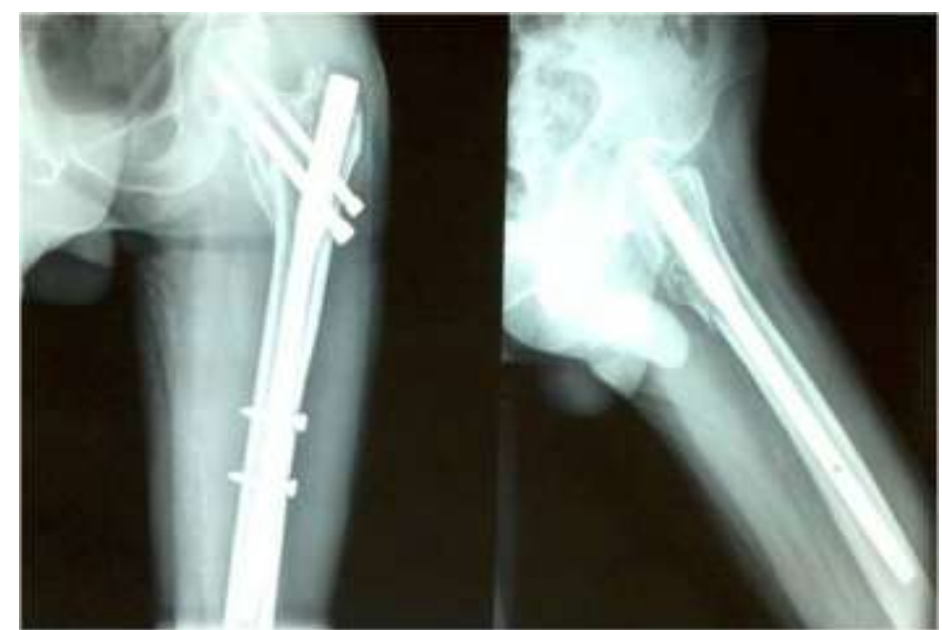

Fig 4:- The Optimal position of lag screw In AP(Inferior) and Lateral(Central).

3 patients required bone grafting while 2 an encirclage wiring to take care of bone loss or excessively displaced bone fragments respectively.Post operative infection was seen in $8 \%$ of patients and needed change of antibiotics and debridement and dressing. Majority of the patients were discharged by $5^{\text {th }}$ post operative day, only few needed longer stay due to infection, daily dressing and debridement or due to associated systemic injuries.After Proximal femur nail internal fixation early partial weight bearing was allowed usually by 2 nd post operative day in all those 
patients having stable internal fixation and not having any associated major illness/ injury/complications.Patients were allowed to bear full weight within 12 weeks in majority of patients according to stability of fixation, degree of comminution, amount of osteoporosis and radiological union. "Z" effect was seen in 3 patients and "reverse Z effect" which is a normal phenomenon occurred in 10 patients.

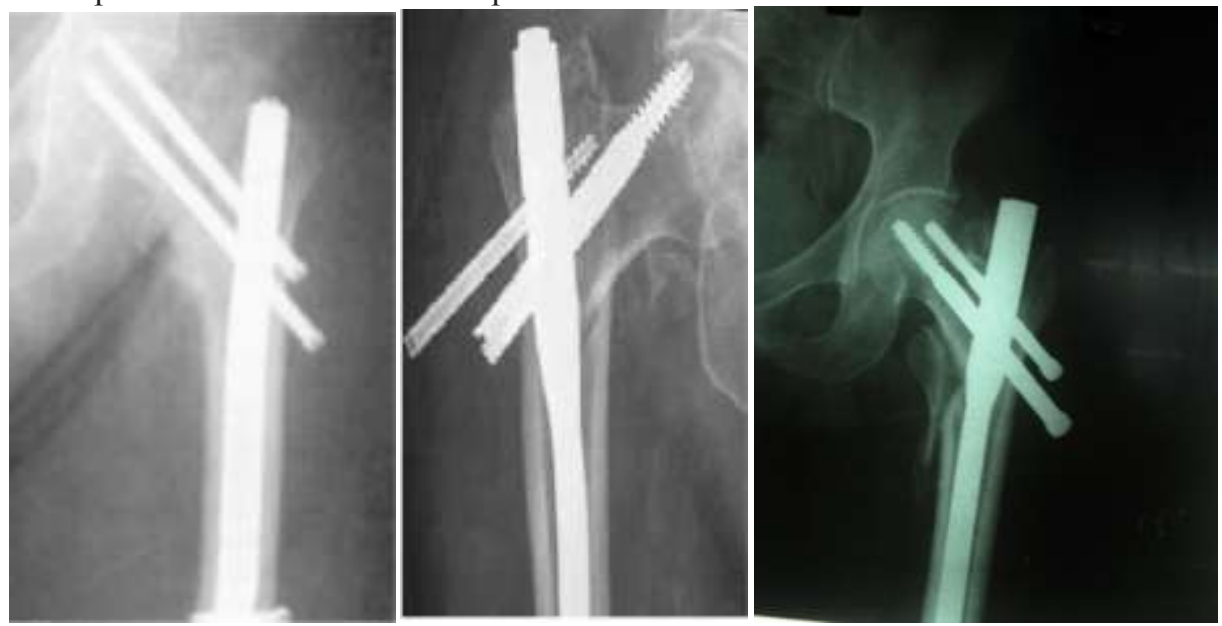

Fig 5:- Z-effect a complication of Improper fixation by Proximal Femoral Nail.

All cases were evaluated according to modified Harris hip score on residual effects on clinical grounds at final examination. Pain and functional capacity are the two basic considerations for this scoring system. In the study group, the walking capacity of majority of patients was 6 blocks or more and most of the patients used no support for walking. Majority of the patients complained of only slight pain at hip on final follow up while $20 \%$ had no pain at all. Based on all the above criteria the functional result according to modified Harris hip score was found to be excellent in $22 \%$, good in $46 \%$, fair in $20 \%$ and poor in only $12 \%$ of patients.

$72 \%$ of the fractures were found to be clinically united by 12 weeks following surgery. In the minority in whom the clinical union was delayed beyond 12 weeks but within 16 weeks were occurred in $24 \%$ while delayed union occurred in 2 patients.In the study series among 32 working employee's, 22 could retain the same job, 6 had to change the job while 4 persons were so incapacitated that could not do any job after the operation, with average duration to return to job was 4.28 months in the group.

\section{Discussion:-}

A Dynamic Hip Screw is the most commonly used implant for intertrochanteric fractures up till now and was considered a gold standard for any type of intertrochanteric fracture. Load bearing in the proximal femur is predominantly through calcar femorale, the lever arm of laterally placed plate is increased so there is a risk of implant cutout. Although many meta analysis and Cochrane library reviewed superiority of DHS over intramedullary devices This was predominantly due to risk of femoral shaft fracture associated with earlier version of gamma nail and complications due to steep learning curve associated with the implant. But, with the advent of proximal femoral nail the complications associated with gamma nail have been reduced and results of proximal femoral nail in treatment of intertrochanteric fractures are comparable or even better than dynamic hip screw. 

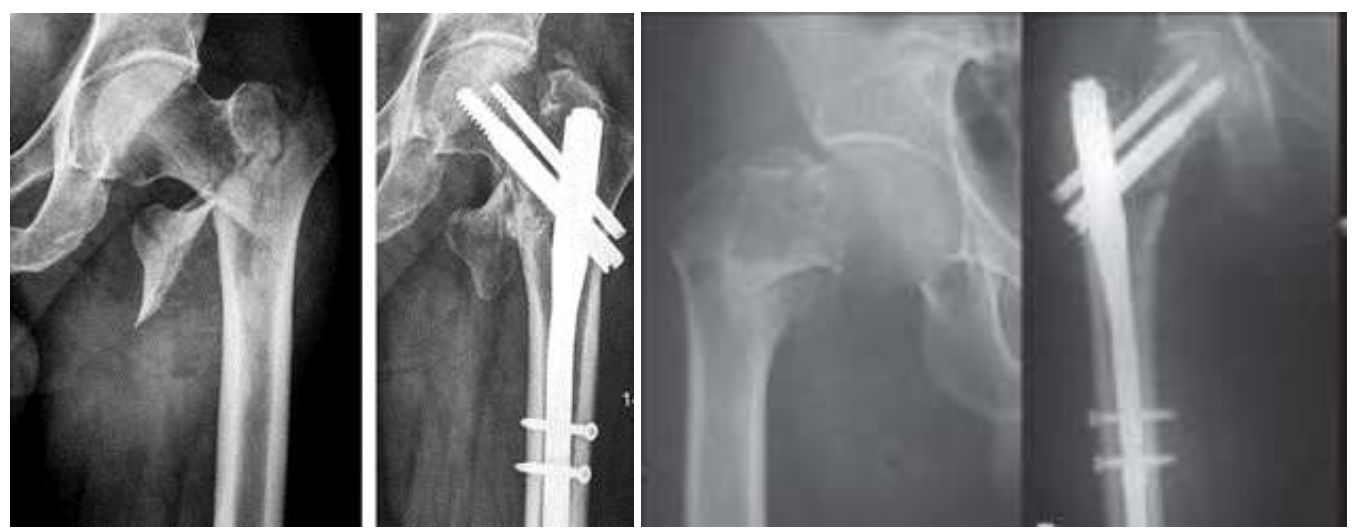

Fig 6:- Preoperative and Postoperative X-rays for unstable intertrochanteric Fracture hip treated with Proximal Femoral Nail.

Traditionally it was the posteromedial comminution which was considered the most important factor in determining the severity of fracture. The importance of the integrity of the lateral femoral wall has been documented recently The lateral wall is the proximal extension of the femoral shaft. This lateral wall is extremely thin in unstable 31 A2 type fracture. The lateral wall in patients treated with dynamic hip screw provides a lateral buttress for the controlled fracture impaction and preventing collapse. Palm et al found that there was an eight times higher risk of re-operation due to technical failure with the gold standard technique of dynamic hip screw in patients with fracture of the lateral femoral wall. This has been attributed to the fact that when the lateral femoral wall is fractured, the fracture line is parallel to the sliding vector of the sliding hip screw, which, as in the reverse oblique intertrochanteric fracture, allows the trochanteric and femoral head and neck fragments to slide laterally and the shaft to slide medially. The fracture complex subsequently disintegrates, with a high risk of failure including cutout of the screw into the hip joint.Unstable fractures should be initially reduced to a slightly valgus position during PFN surgery, because the neck-shaft angle would decrease during the first 6 postoperative weeks.The lag screw should be inserted into the femoral head as deeply as noted in the AP view, and centrally in the lateral view. The tip of the lag screw should always be inferior to the centre of the femoral head.In our study, the lag screw was inserted close to the subchondral bone, and the hip pin superiorly in the femoral head. This resulted in $90 \%$ of the lag screws being inserted at the optimal site (inferior to the centre of the femoral head) and to an optimal depth, thereby achieving rigid fixation. Good reduction of the fracture, and optimal positioning and length of the hip pin and lag screws are crucial for the PFN procedure and reported to yield excellent outcomes. The amount of telescoping was then measured as the lateral prominence of the blade lateral to the edge of the nail. X-ray measurements were made immediately postoperatively, at six weeks postoperatively, and at subsequent follow-up.

\section{PFN has got the following advantages over the routine gold standard DHS:-}

1. less exposure

2. early weight bearing

3. more preferred in unstable patterns with medial cortical communition and lateral wall deficit,and less rate of backout of screw

\section{The disadvantages are:-}

1. more radiation exposure

2. more intraoperative complications

3. more operative time all of which can be reduced with surgical expertise.

For rotational control distal locking screws are almost always necessary. But being a strong and rigid implant as compared to routinely used implants in the past with more medial support in anatomical axis of femur it promoted early weight bearing.

The results of our study regarding fixation of intertrochanteric fractures with lateral cortical breech (31 A3 type fracture) and those with extremely thin lateral cortex (31 A2.2 and A2.3) are highly encouraging with shortening of less than $1 \mathrm{~cm}$ in (approximately $75 \%$ ) patients and close to $95 \%$ return of pre-injury mobility. 


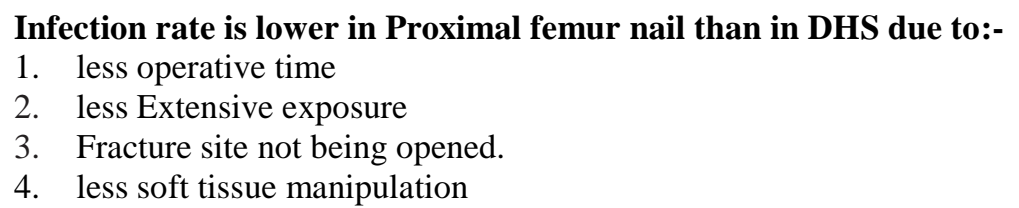

Although a large randomly controlled trial with adequate statistical power is desirable to substantiate/negate the superiority of one implant over the other, our clinical series has validated the fact that proximal femoral nail is an optimum implant for unstable intertrochanteric fractures with good clinical outcome and an acceptable rate of technical complications.

\section{Conclusion:-}

1. Interochanteric fractures commonly occur in elderly persons usually following minor trauma where as in young patients a major trauma is needed to cause this fracture.

2. In the study group average operative time taken for internal fixation with PFN was 79 minutes with average blood loss being $102 \mathrm{ml}$.

3. Stable fixation with near perfect reduction could be achieved in majority of the patients which is the key determining factor in early ambulation.

4. Partial weight bearing could be started as early as $2^{\text {nd }}$ post operative day in suitable patients.

5. Functional assessment according to modified HARRIS HIP SCORE was found to be excellent in $22 \%$ and good in $46 \%$, a major percentage of patients at final follow up.

There was one case of non union found in this series due to distraction at the fracture site, The average union time was 15.16 weeks. To Conclude Proximal Femur Nail is an optimum implant for internal fixation of unstable intertrochanteric fracture with advantages of stable fixation, perfect reduction, early weight bearing and ambulation, shortened hospital stay and improved rate of union with early resumption of independent life style.

\section{References:-}

1. Dimon JC, Hughston JC- Unstable intertrochanteric fracture of hip;J Bone Joint Surg Am.1967;49 A; 440-50.

2. Jensen JS- Trochanteric Fracture,an epidemiological, Clinical and biomechanical study;Acta Orthop Scand,1981,suppl 188;1-100.

3. Pu JS, Liu L, Wang GL, Fang Y, Yang TF. Results of the proximal femoral nail anti-rotation (PFNA) in elderly Chinese patients. Int Orthop.2009;33(5):1441-4, http://dx.doi.org/10.1007/s00264-009-0776-3.

4. Parker MJ, Handoll HH. Gamma and other cephalocondylic intrame-dullary nails versus extramedullary implants for extracapsular hip fractures in adults. Cochrane Database Syst Rev. 2010(9):CD000093.

5. Kokoroghiannis C, Aktselis I, Deligeorgis A, Fragkomichalos E,Papadimas D, Pappadas I. Evolving concepts of stability and intrame-dullary fixation of intertrochanteric fractures--a review. Injury. 2012;43(6):686-93, http://dx.doi.org/10.1016/j.injury.2011.05.031.

6. Sadowski C, Lubbeke A, Saudan M, Riand N, Stern R, Hoffmeyer P.Treatment of reverse oblique and transverse intertrochanteric fractureswith use of an intramedullary nail or a 95 degrees screw-plate: aprospective, randomized study. J Bone Joint Surg Am. 2002;84-A(3):372-81.

7. Murray RC; Trochanteric fracture of femur;J BoneJoint Surg.1949,31B,478.

8. Baumgaertner MR, Curtin SL, Lindskog DM. Intramedullary versus extramedullary fixation for the treatment of intertrochanteric hip fractures. Clin Orthop Relat Res 1998;348:87-94.

9. Simmermacher RK, Bosch AM, Van der Werken C. The AO/ASIF-proximal femoral nail (PFN): a new device for the treatment of unstable proximal femoral fractures.Injury 1999;30:327-32.20.

10. Vidyadhara S, Rao SK. One and two femoral neck screws with intramedullary nails for unstable 1trochanteric fractures of femur in the elderly: randomised clinical trial. Injury 2007;38:806-14.21.

11. Gadegone WM, Salphale YS. Proximal femoral nail:an analysis of 100 cases of proximal femoral fractures with an average follow up of 1 year Int. Orthopaedics 2007;31:403-8.

12. Strauss EJ, Kummer FJ, Koval KJ, Egol KA. The "Z-effect" phenomenon defined: a laboratory study J Orthop Res 2007;25:1568-73.

13. Tyllianakis M, Panagopoulos A, Papadopoulos A, Papasimos S, Mousafiris .Treatment of extracapsular hip fractures with the proximal femoral nail (PFN): long term results in 45 patients. Acta Orthop Belg 2004;70:444-54. 
14. Simmermacher RK, Ljungqvist J, Bail H, Hockertz T, Vochteloo AJ, Ochs U, et al. The new proximal femoral nail antirotation(PFN-A) in daily practice: results of a multicentre clinical study. Injury 2008;39:932-9.

15. Menezes DF, Gamulin A, Noesberger B. Is the proximal femoral nail a suitable implant for treatment of all trochanteric fractures? Clin Orthop Relat Res 2005;439:221-7.

16. Boldin C, Seibert FJ, Fankhauser F, Peicha G, Grechenig W, Szyszkowitz R. The proximal femoral nail (PFN) - a minimal invasive treatment of unstable proximal femoral fractures: a prospective study of 55 patients with a follow-up of 15 months.

17. Acta Orthop Scand 2003;74:53-8. 